\title{
TISSUE MORPHODYNAMICS SHAPING THE EARLY MOUSE EMBRYO
}

Ann E. Sutherland

Department of Cell Biology

University of Virginia Health System

Charlottesville, VA 22908

\section{Address for correspondence:}

Department of Cell Biology

University of Virginia Health System

PO Box 800732

Charlottesville, VA 22908-0732

Tel: 434-243-6711

Email: as9n@virginia.edu 


\begin{abstract}
Generation of the elongated vertebrate body plan from the initially radially symmetrical embryo requires comprehensive changes to tissue form. These shape changes are generated by specific underlying cell behaviors, coordinated in time and space. Major principles and also specifics are emerging, from studies in many model systems, of the cell and physical biology of how regionspecific cell behaviors produce regional tissue morphogenesis, and how these, in turn, are integrated at the level of the embryo. New technical approaches have made it possible more recently, to examine the morphogenesis of the mouse embryo in depth, and to elucidate the underlying cellular mechanisms. This review focuses on recent advances in understanding the cellular basis for the early fundamental events that establish the basic form of the embryo.
\end{abstract}

\title{
Key words
}

Gastrulation

Axial elongation

Morphogenesis

Convergent extension

Planar cell polarity

Mouse

\section{Contents}

1. Introduction

1.1. Passivity vs. activity

2. Formation and migration of distal visceral endoderm (DVE) to anterior visceral endoderm (AVE)

2.1. DVE formation: Potential uterine influence

2.2. Migration and intercalation in the AVE

3. Gastrulation Movements

3.1. Comparative overall cell movements 
3.2. Mechanism of streak formation

3.3. Mechanisms of epithelial-mesenchymal transition at the streak

3.4. Dynamic changes in E-cadherin regulate ingression and migration.

3.5. Dynamics of DE formation

4. Axial morphogenesis

4.1. Ventral folding

4.2. Neural, axial/paraxial elongation: formation of the spinal cord, notochord, and somitic array.

4.2.1. Planar cell polarity regulation of convergent extension.

4.2.2. CE of mouse paraxial mesoderm.

4.2.3. Neural convergent extension in the mouse.

4.2.4. Genetic regulation of specific cell behaviors underlying cell intercalation.

4.2.5. Competition of forces shaping the axis

5. Conclusions

6. Acknowledgements

7. References

\section{Introduction}

Creating an elongated embryo with a distinct head and tail from a spherical ball of cells requires extensive tissue morphogenesis. The changes in tissue shape are driven by specific, coordinated behaviors of the cells that make them up, and these behaviors lead not only to changes in tissue shape, but also to specification and differentiation. Cell function in tissue shape change has been thought about for some time and in some depth. In seminal work, Gustafson and Wolpert [1, 2] noted that, in theory, differential adhesions of lateral and basal surfaces of cells in sheets to one another or to surfaces of extracellular matrix could drive cell shape changes. In turn, these changes applied to a cuboidal cell, and integrated across cell sheets, could cause change in tissue shape. For example, cell thinning or flattening causes spreading of the sheet, cell columnarization or palisading causes shrinkage or contraction of the sheet, and 
cell wedging causes bending of the tissue. Others, such as Holtfreter [3-5], argued that internally driven, cell autonomous, changes in cell shape were also important in behavior of cell sheets, and locally autonomous, if not cell autonomous, changes in cell shape generate endogenous forces that reshape the neural plate $[6,7]$. Current work has built on these pioneering studies, providing evidence for actomyosin-based apical constriction driving bending of cell sheets (invaginations) [8-10], as well as apical-basal shortening with apical constriction [11]. Cell division, even without growth (increase in cell volume), as is the case in many yolky embryos, such as many amphibians [4], can contribute to tissue shape change by being oriented. Cell division with growth has long been thought to drive the folding movements of embryos [12-14], a particularly significant mechanism in embryos that show dramatic growth in early development, including birds and mammals [14, 15]. Intercalation of cells along an axis within the plane of a multilayered tissue can produce a narrower, longer tissue (often called convergent extension, or CE), and cell intercalation normal to the plane of a multilayered tissue (radial intercalation) can thin the tissue $[16,17]$. Finally, movements and associations of cells may be regulated by cell-cell recognition and selective affinity [18], which is the notion that cells recognize one another on contact as similar or different, and that they can show either a positive or negative affinity, seen as a high or low probability of maintaining contact.

\subsection{Passivity vs. activity}

In all cases of tissue shape change, the question arises, is it endogenously driven and active, or is it a passive response to external forces? Many large morphogenic processes involve both active and passive phases, and it is only with detailed analysis of the relationship of cell behavioral changes and mechanical interactions of tissues can this be determined [19]. Only in a very few cases do we know where and how the forces are being generated, and this is particularly true in mammals. Recent advances in live imaging techniques [2023] have made it possible to more fully analyze the morphogenesis of the mouse embryo and to elucidate the underlying cellular mechanisms. This review 
summarizes our current knowledge of the cell behaviors that generate the basic form of the mouse embryo, and identifies areas where further insight is needed.

\section{Formation and migration of the distal visceral endoderm (DVE) to become anterior visceral endoderm (AVE).}

One of the critical morphogenetic events that shapes the early mouse embryo is formation of the DVE at the distal tip of the embryo and its subsequent migration proximally to a position near the boundary with the extraembryonic tissues, to become the AVE ([24-26], reviewed [27]). How the AVE is formed is particularly important because it is a key signaling tissue that regulates establishment of the embryonic anterior/posterior $(\mathrm{A} / \mathrm{P})$ axis through inhibitory effects on Nodal signaling [28-30]. Cells of the AVE produce Cerberus-like 1 (Cer1) and Lefty 1 (Lefty1), inhibiting Nodal signaling anteriorly, inducing differentiation of ectoderm in the underlying epiblast, and restricting the position of the primitive streak to the posterior side $([29,30]$, reviewed $[27,31])$.

\subsection{DVE formation: Potential uterine influence}

A very novel cellular mechanism for the formation of the DVE has been proposed [32], that implicates mechanical constraint by the uterus as a morphogenic force. Circumferential restriction of the early embryo (E5.0) in in vitro culture, mimicking the compression forces of the decidua on the growing embryo in vivo, leads to preferential proximal-distal elongation of the embryo. The mechanical force imposed on the distal tip results in basement membrane breaches that allow extrusion of a small number of epiblast cells into the visceral endoderm (VE) layer, where they become the Cer1-positive cells that form the DVE. However, a recent report [33] calls this mechanism into question, demonstrating DVE formation and migration in embryos cultured in vitro without any physical restraint. Technical advances in in vitro culture of mouse embryos through the implantation stage should facilitate a more thorough analysis of this event to resolve these conflicting findings [34]. 


\subsection{Migration and intercalation in the AVE}

Once established, the DVE undergoes a very unusual migration [24, 25, 35], forming very long basal protrusions that extend in the direction of migration [25, 36]. At the same time, DVE cells maintain their epithelial characteristics, and exchange neighbors along the migration pathway [35, 37]. This behavior not only characterizes the leading DVE cells, but also surrounding cells that will contribute to the AVE [38], establishing this as a coordinated, or collective, cell migration. Genetic studies have identified roles for actin regulators Rac1 and the WAVE complex as well as PTEN in this migration [35, 39, 40], consistent with the active, directed protrusive behavior. The factors that regulate the directionality and extent of migration are currently unknown, but may emanate from the extraembryonic ectoderm (ExE). Regulation of DVE formation relies on repressive factors produced by the ExE [41], and the AVE cells shift from anteriorly- to laterally-directed migration when they reach the boundary with the DE overlying the ExE [25, 35-37] suggesting a regulatory activity associated with this region. The AVE thus represents a very interesting model system for studying coordinated epithelial migration in an epithelium.

\section{Gastrulation movements}

\subsection{Comparative overall cell movements}

Formation of the AVE restricts Nodal signaling to the prospective posterior of the embryo, where it induces formation of the primitive streak and the onset of gastrulation [29], reviewed [27, 42, 43]. The primitive streak is a region of epithelial-mesenchymal transition (EMT) where epiblast cells ingress to generate a new population of mesenchymal cells that give rise to mesoderm and definitive endoderm (DE). The cellular mechanisms underlying this critical morphogenetic event have been most thoroughly studied in chick [44-47] and rabbit embryos [48-52], and much less is known about gastrulation in the mouse [21, 53-57]. The chick and rabbit, which are relatively large, flat disc-shaped embryos at the time of gastrulation, exhibit large-scale movements of cells toward the midline. In the chick, epiblast cells located far laterally in the blastoderm move posteriorly in 
circular whorls on either side of the nascent primitive streak, and when they meet at the posterior midline, they turn anteriorly together to form the streak, a movement known as "polonaise movements" $[46,58]$. Movements in the rabbit epiblast describe $\mathrm{L}$ - and $\mathrm{U}$-shaped patterns from peripheral toward the primitive streak [51]. In both cases, planar intercalation of precursor cells leads to elongation of the streak structure, followed by ingression and migration of mesendoderm $[47,51]$.

By contrast, in the mouse embryo there are no large-scale movements of epiblast cells, and cell intercalation does not appear to play a role in formation or elongation of the streak $[53,54]$. The mouse primitive streak forms by progressive initiation of EMT in the posterior epiblast, beginning at the proximal posterior boundary with the ExE and extending to nearly the distal tip [53]. There is no obvious active migration toward the primitive streak, or cell rearrangement in the epiblast, suggesting that ingression of epiblast cells at the streak provides the force propelling new cells to the streak region [53]. The differences observed between the mouse, chick and rabbit systems may stem from the vast differences in size and morphology of the embryos; chick and rabbit embryos are many times larger than the E6.75 mouse embryo at the start of gastrulation, and are flat, while the mouse embryo is cup-shaped. In addition, while the mesoderm is specified at the embryonic/extraembryonic border in the chick [59], it lies adjacent to the primitive streak in the mouse [60-62] and so does not have to translocate great distances to undergo ingression at the proper place.

\subsection{Mechanism of streak formation.}

Formation of the primitive streak is defined operationally as induction of competence for EMT in the posterior epiblast. The process of primitive streak EMT has three distinct phases; basement membrane loss, ingression, and migration, with specification of mesendoderm fate accompanying ingression and migration. A signaling network comprised of BMP4 from the ExE and Nodal and Wnt3 from the embryonic region is required for streak formation (reviewed [31]), 
because mutants lacking BMP4, Nodal, or Wnt3 do not form a streak and fail to specify mesendoderm.

\subsection{Mechanisms of EMT at the streak.}

Basement membrane loss is required but not sufficient to trigger EMT and ingression of cells from the epiblast [53]. Studies in the chick have demonstrated that the basement membrane is maintained by basal RhoA activity and stabilized basal microtubules in the epiblast cells of the primitive streak [63,64]. Inhibition of RhoA leads to basement membrane loss and down-regulation of integrin $\alpha 6 \beta 1$, and destabilization of microtubules with nocodozole has a similar effect $[63,64]$. These findings are consistent with data showing that constitutive activation of RhoA in the epiblast of the mouse [65] causes failure of ingression and migration and leads to cell accumulation at the primitive streak.

Ingression involves specific changes in cell shape and in cell-cell adhesion [48, $53,63,64,66]$. The cells begin by undergoing apical constriction to become flask-shaped, reduce expression of components of the tight and adherens junctions (e.g. occludin, E-cadherin) and of the apical membrane domain (aPKC) $[53,64]$. As an ingressing cell constricts, the surrounding cells are brought together, and as the cell leaves the epithelium a rosette is formed by the surrounding cells [67]. Note that these rosettes are formed by contraction of the apex of a single cell, rather than contraction of the connected boundaries of a number of cells, as in epithelial cell intercalation ([68] discussed in Section 4.2.2), and they represent very different processes beyond the fact that both involve a myosin mediated contraction.

\subsection{Dynamic changes in E-cadherin regulate ingression and migration.}

The adhesion molecule E-cadherin acts as a trigger for EMT in epiblast cells. Inhibiting cell adhesion in epiblast explants with a function-blocking E-cadherin antibody causes conversion to a mesenchymal phenotype, with a concomitant switch in intermediate filament expression from cytokeratin to vimentin [69]. 
Conversely, retention of E-cadherin is associated with failure of ingression and/or migration. FGF8 and NIK/Map4k4 signaling pathways control E-cadherin expression in parallel [70-73]. FGF8 induces expression of the transcription factor Snail [72], which represses transcription of $c d h 1$ [72, 74, 75]. However, transcriptional repression of the E-cadherin gene alone is not sufficient to alter cell-cell adhesion, as seen in embryos mutant for p38 interacting protein (p38IP) [73], where epiblast cells continue to express E-cadherin protein despite having normal levels of FGF8 and Snail [73]. Analysis of p38IP mutants demonstrated that activation of p38 by NIK/Map4K4 through p38IP leads to downregulation of the E-cadherin protein, which, together with the transcriptional repression by Snail, rapidly eliminates E-cadherin and facilitates mesendoderm migration [73]. Interestingly, evidence for yet another level of E-cadherin regulation during ingression comes from embryos lacking Dapper Antagonist of Beta-catenin 1 (Dact1; [76]). Dact1 binds to Dishevelled (Dvl) and modulates both canonical Wnt/Beta catenin and Wnt/planar cell polarity (PCP) signaling pathways [77-80]. In the primitive streak, Dact1 regulates Van Gogh-like 2 (Vangl2) posttranslationally to reduce E-cadherin in the membrane of epiblast cells [76]. Streak epiblast cells lacking Dact1 maintain E-cadherin localization in the membrane, and ingression fails, particularly in the later, posterior streak, a failure that is ameliorated by reducing Vangl2 levels [76]. Altogether, it appears that destabilization of E-cadherin at the membrane permits ingression, and inhibition of transcription of E-cadherin mRNA, and degradation of existing E-cadherin protein permit migration.

\subsection{Dynamics of DE formation.}

Once they have left the epiblast epithelium and depending on their position within the streak $[62,81]$, mesoderm cells will migrate in one of two ways: proximally to form extraembryonic mesoderm [82], or laterally and anteriorly between the epiblast and the overlying VE to form "wings" of mesoderm [81]. The cells migrate directionally and individually $[53,54,56]$ until they reach the anterior. Cells that are fated to become DE, on the other hand, first exit the primitive 
streak to migrate anteriorly and laterally with the mesoderm [83], and then undergo a mesenchymal to epithelial transition (MET) to intercalate into the VE $[83,84]$. Intercalation occurs at the level of single cells, generating a salt and pepper mix of cells of VE and of DE lineage in the final layer of endoderm ([83, 84]; reviewed [85]). The transcription factors FoxA2 and Sox17 are required in complementary ways for the prospective $D E$ of the foregut and mid-/hind-gut respectively, to intercalate into the VE $[83,85]$. Prospective DE cells lacking FoxA2 can intercalate into the VE, but fail to express the tight junction protein claudin 4, or to localize E-cadherin and ZO-1 properly, and are subsequently excluded from the epithelial layer [86]. This implicates changes in apico-basal polarity and junctional adhesion proteins as part of the cellular mechanism for the MET.

\section{Elongation of the body plan: Axial and paraxial morphogenesis.}

The initial stages of gastrulation are characterized by extensive ingression and migration of mesendoderm, which place the definitive germ layers in their proper positions and are accompanied by significant changes in overall size, but little change in overall shape of the embryo [87]. However, this is followed by very dramatic changes in tissue shape as the embryonic axis undergoes morphogenesis (Fig. 1). In this phase, the anterior portion of the axis becomes concave, folding perpendicular to the A/P axis of the embryo to form the head folds. The axial and paraxial mesoderm and the overlying neural ectoderm of the trunk region narrow and lengthen extensively, and the neural ectoderm and the gut endoderm fold along the A/P axis of the embryo to form the neural tube and the gut tube, respectively (Movie 1.).

\subsection{Cranial morphogenesis: Formation of the head folds.}

Axial morphogenesis begins with thickening and flattening of the anterior half of the embryo to form the neural plate [87], followed by infolding and expansion in a concave shape to form the head folds on either side of the neural groove (Fig. 1). Expansion of the head folds proximally and anteriorly helps rotate the cardiac 
mesoderm distally, placing it posterior and ventral to the future cranial region (Movie 1; reviewed [88]). In addition, this rotation and folding creates the foregut pocket, the anterior opening of the future gut tube (Fig. 1). This represents an additional function of the AVE in specifying axial development, as BMP2 produced by the AVE signals to the anterior epiblast to initiate this morphogenesis [89]. Interestingly, a similar function in inducing neural head fold formation is seen for the anterior endoderm in the chick embryo [90].

Several genetic mutants, in addition to BMP2, affect head fold formation, namely Flrt3 (fibronectin leucine-rich transmembrane protein 3) [91, 92], the transcription factor Gata4 [93, 94] , Hgs/Hrs (HGF related tyrosine kinase substrate; [95]), and the proprotein convertase Furin [96], however it is completely uncharacterized at the cellular level. There are very important tissue-level changes occurring that must involve cell behaviors that generate specific forces. The first is the infolding of the epiblast. The action of BMP2 may play a role in driving cell shape changes in the neighboring epiblast and endoderm to generate this tissue change [89]. These are likely complementary shape changes on the part of the endoderm and the epiblast: for example, apical constriction for the endoderm, and basal constriction/apical expansion for the neural plate [97, 98]. The increase in length of the cranial region likely drives neural fold expansion by CE. The inflection points just posterior to the AVE and at approximately the posterior hindbrain boundary, where the curvature of the embryo changes from concave to convex (Fig. 1, Movie 1) appear to be critical elements of the infolding process. These regions may act as stabilizing points against which CE of the cranial region exerts force to expand the head folds. Needless to say, these events deserve much more in depth analysis to characterize the underlying cell behaviors.

4.2. Neural, axial/paraxial elongation: formation of the spinal cord, notochord, and somitic array. 
The body axis is formed through anterior-posterior elongation of the posterior neural plate and the associated axial and paraxial mesoderm, which lays the foundations for the spinal cord and vertebral column. Lengthening and narrowing of these tissues is driven, in all chordates, by convergent extension (CE), a kinematic description of tissue narrowing (convergence) with commensurate elongation (extension). CE can occur as a passive stretching of tissue due to external tensile forces, or, of more interest here, as an active, force-producing process in which cells become polarized transverse to the axis of elongation and actively intercalate between one another, acting as wedges to force either neighbors apart to form a narrower, longer tissue (reviewed [17]).

Intercalation of mesenchymal (non-epithelial) cells occurs as cell protrusive activity [99], contraction of the associated actomyosin cytoskeleton [100, 101], and cell traction on neighbors all become bi-polarized in the mediolateral direction, and are collectively known as mediolateral intercalation behavior (MIB). MIB generates tensile forces that result in cell elongation, alignment, and wedging between one another along the mediolateral axis to form a narrower, longer array [102]. The mesenchymal mode of cell intercalation was originally defined in the mesodermal tissue of the frog [103, 104] and fish [105-107], and since then in many systems [17].

Epithelial tissues also undergo CE, and two major cellular mechanisms have been established for this. Analogous to the MIB of mesenchymal CE, cells in the C. elegans epidermis intercalate by insertion of basolateral protrusions between neighboring cells followed by "plowing" of the remainder of the cell through the adherens junctions as it moves forward [108-110]. In contrast, in the Drosophila germ band, cells intercalate through polarized apical junctional boundary shortening without basal protrusive activity, resulting in movement of cells between one another and into contact with new neighbors, either in pairs (the T1/T2/T3 mode) [111] or in groups (the rosette mode) [68]. The cells then "resolve" into narrower, longer arrays by exchange of neighbors. In addition to 
polarized cell intercalation, polarized epithelial cell shape change has also been implicated in convergence, though not much extension, and neural plate bending in the chick embryo [112].

\subsubsection{Planar cell polarity regulation of convergent extension.}

A major advance in understanding the genetic and molecular mechanisms of these polarized cell behaviors in vertebrate tissues was the discovery that components of the planar cell polarity (PCP) signaling pathway, which specifies polarity within the plane of the tissue in Drosophila [113-116] are also essential for the polarized cell behaviors underlying $C E$ in vertebrates [117-121]. The noncanonical Wnt/PCP pathway was identified and characterized in vertebrates on the basis that it polarizes cell behaviors and cell structure in vertebrates, and shares many components with the Drosophila pathway (reviewed in [122-124]). It consists of Frizzled (Fz) receptors and proteins homologous to the Drosophila Van Gogh, Starry night/Flamingo, Dishevelled, Prickle, and Diego, and, in addition, Wnt5a and Wnt11 ligands for Fz, whereas in Drosophila no Wnt ligand has been identified thus far [125]. In frogs [118, 119] and fish [117], perturbation of this pathway results in failure of MIB in the presumptive mesoderm and neural plate [126-129].

In mice, mutations of Wnt/PCP pathway genes, including Van Gogh-like (Vang/1/Vangl2) [130-133], Flamingo (Celsr1) [134], Frizzled (Fz3/Fz6) [135], and Dishevelled (Dv/1/2) $[136,137]$ yield mice with short body axes and an open neural tube posterior to the hind brain, a phenotype known as craniorachischisis (CRN) (Fig. 2). In addition, each of these mutations also affects the polarized organization of hair cells in the inner ear, as well as CE of the cochlea (reviewed in [138]). Mutations in two other genes, Protein tyrosine kinase 7 (Ptk7) and Scribble1 (Scrib) have similar defects and interact genetically with Vangl2 and Celsr1 $[132,139,140]$. The combined phenotype of CRN and hair cell polarity defects has become the hallmark of Wnt/PCP disruption in mammals. 
Importantly, mutations in the human genes VANGL1, VANGL2, DVL2, CELSR1, $P K 1$, and SCRIB1 are also associated with neural tube defects [141-146]. Within the chordates, the function of this pathway in regulating CE is conserved in ascidians [147], fish [117, 148], frogs [118, 149-152] and mice, and has provided a way to analyze the cellular and molecular bases of neural tube defects in humans $[123,143,144,146,153,154]$.

\subsubsection{CE of mouse paraxial mesoderm.}

This mesenchymal mode of CE through MIB characterizes the behavior of the mouse paraxial mesoderm (Movie 2; [155]). It is induced as these cells leave the primitive streak by multipolar, anteriorly directed migration, and then elongate and orient their long axis towards the midline of the embryo [155]. As they progress anteriorly in the presomitic files, they further elongate and polarize their protrusive activity to the medial and lateral ends [155]. As they progress from multipolar to bipolar protrusive activity, the cells undergo a transition from directed migration, first to a zig-zag movement that leads to very promiscuous and inefficient neighbor exchange, and then to a very conservative, efficient MIB that leads to significant change in tissue shape. The convergence of presomitic mesoderm through MIB leads to extension, but also to thickening through radial cell movement, so overall the paraxial mesoderm becomes narrower, longer, and thicker. The somites are thus relatively cuboidal in shape.

\subsubsection{Neural convergent extension in the mouse.}

The neural plate of the mouse embryo is a pseudo-stratified epithelium, which is a single cell layer at the time that axial elongation occurs. The trunk neural plate undergoes CE through mediolateral intercalation (Movie 3), and, similar to the germ band of Drosophila, the neural epithelial cells undergo apical junctional neighbor exchange through both T1-T2-T3 rearrangements and rosette formation and resolution [20], as well as single-cell intercalation, a mode not seen in the Drosophila germ band. There is also substantial cell growth and proliferation 
within the neural plate, which contributes to CE indirectly by increasing the tissue volume.

Mouse neural cells are also elongated basally along the mediolateral axis of the embryo, and exhibit MIB [20]. Notably, the apical junctional intercalation and the polarized basal MIB lead the cell in the intercalation process with equal frequency, suggesting that both actively contribute to the process [20]. Thus the mouse neural plate is an example in which the junctional rearrangement models and basal MIB models co-exist, which raises the question of what role the vertebrate, non-canonical PCP pathway has in each. Neural CE does not drive thickening of the tissue by radial cell movement such as is seen in the paraxial mesoderm, but the cells elongate in the apical-basal dimension and constrict their apical area, becoming somewhat cone-shaped [20] a shape change nearly universally associated with bending of epithelial sheets [102].

\subsubsection{Genetic regulation of specific cell behaviors underlying cell intercalation.}

Mutations in a number of genes result in failure of axis elongation and/or CRN, but few have been characterized in terms of what they do to the underlying cell behavior, a critical step in establishing a mechanism by which genes affect tissue morphodynamics.

To date, the effect of disrupting Wnt/PCP signaling components on mesodermal cell behavior has been extensively analyzed only in the Ptk7 mutant [155]. Analysis of the Ptk7 mutant established that the key event is the signal triggering elongation and orientation of prospective somitic mesoderm as they leave the streak. The nature of this signal unknown, but clearly involves the function of Ptk7. In the absence of Ptk7 the paraxial mesoderm cells fail to elongate, orient, or convert to bipolar protrusive activity, but continue their multipolar, anteriorly directed migration. As a result, in the absence of CE the presomitic tissue is very short in the anterior-posterior dimension, and very wide in the mediolateral 
dimension, leading to somites that are rectangular rather than cuboidal [140, 155]. Surprisingly, the loss of convergence also uncovered a previously undetected radial intercalation behavior in the pre-somitic mesoderm [155]. In the Ptk7 mutant, active radial intercalation of the presomitic mesoderm thins the tissue and increases its area, thus adding to the mediolateral extent of each somite.

Two mutant mouse strains that exhibit CRN have been analyzed for effects on neural $C E$, and have illuminated some of the critical mechanisms. Embryos lacking Ptk7 exhibit almost complete failure of neural CE, while $L p$ mutant embryos have significantly decreased CE but do elongate to a greater extent than the Ptk7 mutant [20]. Interestingly, the two mutants have completely different effects on cell behavior. Neural cells in the $L p$ mutant are mediolaterally elongated basally and exhibit normally polarized basolateral protrusive activity and normal polarity of apical junctional rearrangement and neighbor exchange. However, they rearrange only half as often as the wild-type, and the effect appears to be localized to the apical region. In contrast, in the PTK7 mutant embryo the cells rearrange with normal frequency but with randomized direction. In addition, the basal ends are not elongated along the mediolateral axis, and the basolateral protrusions are randomly distributed.

These two mutant lines illustrate that neural CE requires both polarized intercalation and also a frequency of cell rearrangement sufficient to generate normal elongation. In addition, the basal and apical ends of neural cells must cooperate to promote cell rearrangement in this system, as the normal basal protrusive activity in the $L p$ mutant cells was not sufficient to promote normal frequency of cell rearrangement. This cooperative behavior is in contrast to what is seen in the Drosophila germ band, where apical rearrangement appears to be the primary driving mechanism $[68,111]$, and to what is seen in the $C$. elegans epidermis, where MIB is the primary driver $[108,110]$. 
The fact that the $L p$ mutation did not affect the polarity of either protrusive activity or cell intercalation was surprising, because Vang in Drosophila and Vangl in frog, fish, and mouse have been shown to affect cell and tissue polarity [132, $148,151,152,156]$. The lack of effect on polarity of neural CE may reflect compensatory activity of Vangl 1 in specifying polarity [133], or it may be that the core Wnt/PCP signaling complexes are not required for polarity in the neural epithelium in the same way as in other epithelia. The effect that the $L p$ mutation has on apical junctional rearrangement, for example, may indicate a role for Vangl2 in regulating cadherin dynamics, similar to what is seen in the primitive streak [76]. More in-depth analysis of cell behavior in embryos lacking PCP components is needed to clarify the function of PCP signaling in CE.

\subsubsection{Competition of forces shaping the axis.}

Analysis of mesodermal and neural CE illustrates a general principle of how cell behaviors generate competing forces that lead to the final tissue form. There are three distinct forces at work in the mouse axis. The first is proliferation and growth, which is not polarized and thus generates tissue expansion in all dimensions ( $\mathrm{A} / \mathrm{P}$, mediolateral, dorsal-ventral). The second is a mediolateral convergence force generated by MIB, which restrains lateral tissue expansion, channeling it instead along either the A/P axis (extension) or along the dorsalventral axis (radial de-intercalation or thickening) (Fig. 2). Finally, there is a radial intercalation force in the paraxial mesoderm that restrains tissue expansion in the dorsal-ventral dimension, channeling it instead along either the A/P axis (extension) or the mediolateral axis (thinning) (Fig. 2). The epithelial nature of the neural tissue restrains expansion in the dorsal-ventral dimension, leading to apical-basal lengthening in response to mediolateral convergence force. The balance of the mediolateral convergence and radial intercalation forces in the context of constant growth pressure and a consistent $A / P$ resistance to extension determines the ultimate shape of the tissue: more mediolateral convergence force and less radial intercalation force give both elongation and thickening, while 
more radial intercalation force and less mediolateral convergence force leads to extension and tissue thinning. The mouse model also provides a novel insight into how cryptic cell behaviors can help shape a tissue, as an underlying (unseen) cellular process may be at work countering tissue movements occurring in an opposite direction. During normal development, the pre-somitic mesoderm thickens substantially due to cells leaving the planar surface, the opposite of what is expected from radial intercalation. But in Ptk7 mutants, the driving convergence force is deleted, revealing the unopposed and very active radial intercalation that dramatically thins the pre-somitic mesoderm. Thus, during normal development the radial intercalation force cannot be detected because it is not as great as the thickening generated by the mediolateral convergence force, but it acts to reduce thickening and promote tissue extension.

The mouse embryo provides clear alternative examples of how these competing forces shape a tissue. In the paraxial mesoderm, a relatively greater mediolateral convergence force pairs with proliferation to generate both extension and thickening, whereas a relatively smaller mediolateral convergence force pairs with proliferation in the neural plate to generate extension alone [20, 155]. At the level of the embryo the balance between the overall extension of each of these tissues gives rise to the shape of the axis, and failure in one tissue is likely to lead to axial defects in the other. Indeed, mutants that affect paraxial mesoderm morphogenesis (e.g. alpha5 integrin [157] or fibronectin [158]) lead to kinking and waviness in the neural tube, which may represent unbalanced extension of the neural tissue in the absence of appropriate extension of the mesoderm.

\section{Conclusions}

By analyzing the morphogenesis of the early mouse embryo in greater cellular detail we have shown that many cellular behaviors identified in other model systems, both vertebrate and invertebrate, contribute to tissue morphodynamics in mammals. In particular, the mesenchymal MIB seen in frogs and fish axial and 
paraxial mesoderm $[16,17]$ characterizes mouse mesodermal cells, and both the apical junctional shortening and basal protrusive activity model of Drosophila and C. elegans, respectively, describe the behavior of mouse neural cells. However, there are clear differences in the repertoire of cell behaviors that mouse cells use to drive CE from those described in other systems, and distinct differences in the regulation of these behaviors by PCP signaling. These may relate to the differences in the context in which these cell behaviors act, in particular the mechanical force landscape in which gastrulation and axial elongation occur in the different embryos, as well as the significant contribution that growth makes to morphogenesis in the mouse embryo compared to frog, fish, and fly embryos. In this context it is interesting that changes in hydrostatic pressure within the amniotic cavity can regulate CE in mouse axial mesoderm [159]. Likewise, given the substantial difference in morphological contexts for cranial and trunk neural tube morphogenesis, it is intriguing that mouse mutants that give rise to cranial neural tube dysgenesis do not affect trunk neural tube morphogenesis and viceversa [160]. At the moment the mechanical aspects of mouse development remain to be identified; we do not know the full range of forces that are acting at the tissue and embryo level nor how they are related to the cell behaviors that we have identified, and those yet to be characterized. It will be important not only to further explore the cellular behavior that underlie mouse morphogenesis, but also to develop methods for characterizing the mechanical forces that the cells both sense and generate to effect changes at the tissue level.

\section{Acknowledgements}

I thank current and former members of my lab and many collaborators for their invaluable contributions to the research described. I also thank Dr. Raymond Keller for helpful comments on the manuscript and for providing the artwork for Figure 2. Our work on mouse axial morphogenesis was supported by the National Science Foundation (IOS 1051294). 


\section{References cited}

[1] Gustafson T, Wolpert L. The Cellular Basis of Morphogenesis and Sea Urchin Development. Int Rev Cytol 1963;15:139-214.

[2] Gustafson T, Wolpert L. Cellular movement and contact in sea urchin morphogenesis. Biol Rev Camb Philos Soc 1967;42:442-98.

[3] Holtfreter J. A study of the mechanics of gastrulation. Part II. J exp Zool 1944;95:171-212.

[4] Holtfreter J. A study of the mechanics of gastrulation. Part I. J exp Zool 1943;94:261-318.

[5] Holtfreter J. Properties and function of the surface coat in amphibian embryos. J exp Zool 1943;93:251-323.

[6] Burnside MB, Jacobson AG. Analysis of morphogenetic movements in the neural plate of the newt Taricha torosa. Dev Biol 1968;18:537-52.

[7] Jacobson AG, Gordon R. Changes in the shape of the developing vertebrate nervous system analyzed experimentally, mathematically and by computer simulation. J Exp Zool 1976;197:191-246.

[8] Kam Z, Minden JS, Agard DA, Sedat JW, Leptin M. Drosophila gastrulation: analysis of cell shape changes in living embryos by three-dimensional fluorescence microscopy. Development 1991;112(2):365-70.

[9] Leptin M, Grunewald B. Cell shape changes during gastrulation in Drosophila. Development 1990;110(1):73-84.

[10] Mason FM, Tworoger M, Martin AC. Apical domain polarization localizes actinmyosin activity to drive ratchet-like apical constriction. Nat Cell Biol 2013;15:92636.

[11] Sherrard K, Robin F, Lemaire P, Munro E. Sequential activation of apical and basolateral contractility drives ascidian endoderm invagination. Curr Biol 2010;20:1499-510.

[12] Miller SA. Differential proliferation in morphogenesis of lateral body folds. J Exp Zool 1982;221:205-11.

[13] Miller SA, Adornato M, Briglin A, Cavanaugh M, Christian T, Jewett K, et al. Domains of differential cell proliferation suggest hinged folding in avian gut endoderm. Dev Dyn 1999;216:398-410.

[14] Miller SA, Bresee KL, Michaelson CL, Tyrell DA. Domains of differential cell proliferation and formation of amnion folds in chick embryo ectoderm. Anat Rec 1994;238:225-36.

[15] Snow MHL. Gastrulation in the mouse: Growth and regionalization of the epiblast. J Embryol Exp Morph 1977;42:293-303.

[16] Keller R, Davidson L, Edlund A, Elul T, Ezin M, Shook D, et al. Mechanisms of convergence and extension by cell intercalation. Philos Trans R Soc Lond B Biol Sci 2000;355:897-922.

[17] Keller R. Shaping the vertebrate body plan by polarized embryonic cell movements. Science 2002;298:1950-4. 
[18] Holtfreter J. Tissue affinity, a means of embryonic morphogenesis. In: ?, editor.? ?1939.

[19] Butler LC, Blanchard GB, Kabla AJ, Lawrence NJ, Welchman DP, Mahadevan L, et al. Cell shape changes indicate a role for extrinsic tensile forces in Drosophila germband extension. Nat Cell Biol 2009;11:859-64.

[20] Williams M, Yen W, Lu X, Sutherland A. Distinct apical and basolateral mechanisms drive planar cell polarity-dependent convergent extension of the mouse neural plate. Dev Cell 2014;29:34-46.

[21] Udan RS, Piazza VG, Hsu CW, Hadjantonakis AK, Dickinson ME. Quantitative imaging of cell dynamics in mouse embryos using light-sheet microscopy. Development 2014;141:4406-14.

[22] Xenopoulos P, Nowotschin S, Hadjantonakis AK. Live imaging fluorescent proteins in early mouse embryos. Methods Enzymol 2012;506:361-89.

[23] Garcia MD, Udan RS, Hadjantonakis AK, Dickinson ME. Live imaging of mouse embryos. Cold Spring Harb Protoc 2011;2011:pdb top104.

[24] Rivera-Perez JA, Mager J, Magnuson T. Dynamic morphogenetic events characterize the mouse visceral endoderm. Dev Biol 2003;261:470-87.

[25] Srinivas S, Rodriguez T, Clements M, Smith JC, Beddington RS. Active cell migration drives the unilateral movements of the anterior visceral endoderm. Development 2004;131:1157-64.

[26] Thomas P, Beddington R. Anterior primitive endoderm may be responsible for patterning the anterior neural plate in the mouse embryo. Curr Biol 1996;6:148796.

[27] Stower MJ, Srinivas S. Heading forwards: anterior visceral endoderm migration in patterning the mouse embryo. Philos Trans R Soc Lond B Biol Sci 2014;369.

[28] Perea-Gomez A, Rhinn M, Ang SL. Role of the anterior visceral endoderm in restricting posterior signals in the mouse embryo. Int J Dev Biol 2001;45:311-20. [29] Perea-Gomez A, Vella FD, Shawlot W, Oulad-Abdelghani M, Chazaud C, Meno C, et al. Nodal antagonists in the anterior visceral endoderm prevent the formation of multiple primitive streaks. Dev Cell 2002;3:745-56.

[30] Yamamoto M, Saijoh Y, Perea-Gomez A, Shawlot W, Behringer RR, Ang SL, et al. Nodal antagonists regulate formation of the anteroposterior axis of the mouse embryo. Nature 2004;428:387-92.

[31] Robertson EJ. Dose-dependent Nodal/Smad signals pattern the early mouse embryo. Semin Cell Dev Biol 2014;32:73-9.

[32] Hiramatsu R, Matsuoka T, Kimura-Yoshida C, Han SW, Mochida K, Adachi T, et al. External mechanical cues trigger the establishment of the anterior-posterior axis in early mouse embryos. Dev Cell 2013;27:131-44.

[33] Bedzhov I, Bialecka M, Zielinska A, Kosalka J, Antonica F, Thompson AJ, et al. Development of the anterior-posterior axis is a self-organizing process in the absence of maternal cues in the mouse embryo. Cell Res 2015.

[34] Bedzhov I, Leung CY, Bialecka M, Zernicka-Goetz M. In vitro culture of mouse blastocysts beyond the implantation stages. Nat Protoc 2014;9:2732-9.

[35] Migeotte I, Omelchenko T, Hall A, Anderson KV. Rac1-dependent collective cell migration is required for specification of the anterior-posterior body axis of the mouse. PLoS Biol 2010;8:e1000442. 
[36] Takaoka K, Yamamoto M, Hamada H. Origin and role of distal visceral endoderm, a group of cells that determines anterior-posterior polarity of the mouse embryo. Nat Cell Biol 2011;13:743-52.

[37] Trichas G, Joyce B, Crompton LA, Wilkins V, Clements M, Tada M, et al. Nodal dependent differential localisation of dishevelled-2 demarcates regions of differing cell behaviour in the visceral endoderm. PLoS Biol 2011;9:e1001019.

[38] Mazari E, Zhao X, Migeotte I, Collignon J, Gosse C, Perea-Gomez A. A microdevice to locally electroporate embryos with high efficiency and reduced cell damage. Development 2014;141:2349-59.

[39] Bloomekatz J, Grego-Bessa J, Migeotte I, Anderson KV. Pten regulates collective cell migration during specification of the anterior-posterior axis of the mouse embryo. Dev Biol 2012;364:192-201.

[40] Rakeman AS, Anderson KV. Axis specification and morphogenesis in the mouse embryo require Nap1, a regulator of WAVE-mediated actin branching. Development 2006;133:3075-83.

[41] Rodriguez TA, Srinivas S, Clements MP, Smith JC, Beddington RS. Induction and migration of the anterior visceral endoderm is regulated by the extra-embryonic ectoderm. Development 2005;132:2513-20.

[42] Srinivas S. The anterior visceral endoderm-turning heads. Genesis 2006;44:565-72.

[43] Arnold SJ, Robertson EJ. Making a commitment: cell lineage allocation and axis patterning in the early mouse embryo. Nat Rev Mol Cell Biol 2009;10:91-103.

[44] Lawson A, Schoenwolf GC. Cell populations and morphogenetic movements underlying formation of the avian primitive streak and organizer. Genesis 2001;29:188-95.

[45] Lawson A, Schoenwolf GC. New insights into critical events of avian gastrulation. Anat Rec 2001;262:238-52.

[46] Chuai M, Zeng W, Yang X, Boychenko V, Glazier JA, Weijer CJ. Cell movement during chick primitive streak formation. Dev Biol 2006;296:137-49.

[47] Voiculescu O, Bertocchini F, Wolpert L, Keller RE, Stern CD. The amniote primitive streak is defined by epithelial cell intercalation before gastrulation. Nature 2007;449:1049-52.

[48] Viebahn C. Epithelio-mesenchymal transformation during formation of the mesoderm in the mammalian embryo. Acta Anat (Basel) 1995;154:79-97.

[49] Viebahn C, Mayer B, Miething A. Morphology of incipient mesoderm formation in the rabbit embryo: a light- and retrospective electron-microscopic study. Acta Anat (Basel) 1995;154:99-110.

[50] Viebahn C. Hensen's node. Genesis 2001;29:96-103.

[51] Halacheva V, Fuchs M, Donitz J, Reupke T, Puschel B, Viebahn C. Planar cell movements and oriented cell division during early primitive streak formation in the mammalian embryo. Dev Dyn 2011;240:1905-16.

[52] Stankova V, Tsikolia N, Viebahn C. Rho kinase activity controls directional cell movements during primitive streak formation in the rabbit embryo. Development 2015;142:92-8. 
[53] Williams M, Burdsal C, Periasamy A, Lewandoski M, Sutherland A. Mouse primitive streak forms in situ by initiation of epithelial to mesenchymal transition without migration of a cell population. Dev Dyn 2012;241:270-83. [54] Ichikawa T, Nakazato K, Keller PJ, Kajiura-Kobayashi H, Stelzer EH, Mochizuki A, et al. Live imaging of whole mouse embryos during gastrulation: migration analyses of epiblast and mesodermal cells. PLoS One 2013;8:e64506. [55] Ichikawa T, Nakazato K, Keller PJ, Kajiura-Kobayashi H, Stelzer EH, Mochizuki $\mathrm{A}$, et al. Live imaging and quantitative analysis of gastrulation in mouse embryos using light-sheet microscopy and 3D tracking tools. Nat Protoc 2014;9:575-85. [56] Nakatsuji N, Snow MH, Wylie CC. Cinemicrographic study of the cell movement in the primitive-streak-stage mouse embryo. J Embryol Exp Morphol 1986;96:99109.

[57] Smith JL, Gesteland KM, Schoenwolf GC. Prospective fate map of the mouse primitive streak at 7.5 days of gestation. Dev Dyn 1994;201:279-89.

[58] Cui C, Yang X, Chuai M, Glazier JA, Weijer CJ. Analysis of tissue flow patterns during primitive streak formation in the chick embryo. Dev Biol 2005;284:37-47. [59] Chuai M, Weijer CJ. The mechanisms underlying primitive streak formation in the chick embryo. Curr Top Dev Biol 2008;81:135-56.

[60] Lawson KA, Pedersen RA. Clonal analysis of cell fate during gastrulation and early neurulation in the mouse. Ciba Found Symp 1992;165:3-21; discussion -6. [61] Wilson V, Beddington RS. Cell fate and morphogenetic movement in the late mouse primitive streak. Mech Dev 1996;55:79-89.

[62] Tam PP, Beddington RS. The formation of mesodermal tissues in the mouse embryo during gastrulation and early organogenesis. Development 1987;99:109-26. [63] Nakaya Y, Sheng G. An amicable separation: Chick's way of doing EMT. Cell Adh Migr 2009;3:160-3.

[64] Nakaya Y, Sukowati EW, Wu Y, Sheng G. RhoA and microtubule dynamics control cell-basement membrane interaction in EMT during gastrulation. Nat Cell Biol 2008;10:765-75.

[65] Fuse T, Kanai Y, Kanai-Azuma M, Suzuki M, Nakamura K, Mori H, et al. Conditional activation of RhoA suppresses the epithelial to mesenchymal transition at the primitive streak during mouse gastrulation. Biochem Biophys Res Commun 2004;318:665-72.

[66] Tam PP, Williams EA, Chan WY. Gastrulation in the mouse embryo: ultrastructural and molecular aspects of germ layer morphogenesis. Microsc Res Tech 1993;26:301-28.

[67] Wagstaff LJ, Bellett G, Mogensen MM, Munsterberg A. Multicellular rosette formation during cell ingression in the avian primitive streak. Dev Dyn 2008;237:91-6.

[68] Blankenship JT, Backovic ST, Sanny JS, Weitz O, Zallen JA. Multicellular rosette formation links planar cell polarity to tissue morphogenesis. Dev Cell 2006;11:45970.

[69] Burdsal CA, Damsky CH, Pedersen RA. The role of E-cadherin and integrins in mesoderm differentiation and migration at the mammalian primitive streak. Development 1993;118:829-44. 
[70] Yamaguchi TP, Harpal K, Henkemeyer M, Rossant J. fgfr-1 is required for embryonic growth and mesodermal patterning during mouse gastrulation. Genes Dev 1994;8:3032-44.

[71] Ciruna BG, Schwartz L, Harpal K, Yamaguchi TP, Rossant J. Chimeric analysis of fibroblast growth factor receptor-1 (Fgfr1) function: a role for FGFR1 in morphogenetic movement through the primitive streak. Development 1997;124:2829-41.

[72] Ciruna B, Rossant J. FGF signaling regulates mesoderm cell fate specification and morphogenetic movement at the primitive streak. Dev Cell 2001;1:37-49. [73] Zohn IE, Li Y, Skolnik EY, Anderson KV, Han J, Niswander L. p38 and a p38interacting protein are critical for downregulation of E-cadherin during mouse gastrulation. Cell 2006;125:957-69.

[74] Batlle E, Sancho E, Franci C, Dominguez D, Monfar M, Baulida J, et al. The transcription factor snail is a repressor of E-cadherin gene expression in epithelial tumour cells. Nat Cell Biol 2000;2:84-9.

[75] Cano A, Perez-Moreno MA, Rodrigo I, Locascio A, Blanco MJ, del Barrio MG, et al. The transcription factor snail controls epithelial-mesenchymal transitions by repressing E-cadherin expression. Nat Cell Biol 2000;2:76-83.

[76] Suriben R, Kivimae S, Fisher DA, Moon RT, Cheyette BN. Posterior malformations in Dact1 mutant mice arise through misregulated Vangl2 at the primitive streak. Nat Genet 2009;41:977-85.

[77] Cheyette BN, Waxman JS, Miller JR, Takemaru K, Sheldahl LC, Khlebtsova N, et al. Dapper, a Dishevelled-associated antagonist of beta-catenin and JNK signaling, is required for notochord formation. Dev Cell 2002;2:449-61.

[78] Gloy J, Hikasa H, Sokol SY. Frodo interacts with Dishevelled to transduce Wnt signals. Nat Cell Biol 2002;4:351-7.

[79] Zhang L, Gao X, Wen J, Ning Y, Chen YG. Dapper 1 antagonizes Wht signaling by promoting dishevelled degradation. J Biol Chem 2006;281:8607-12.

[80] Lagathu C, Christodoulides C, Virtue S, Cawthorn WP, Franzin C, Kimber WA, et al. Dact1, a nutritionally regulated preadipocyte gene, controls adipogenesis by coordinating the Wnt/beta-catenin signaling network. Diabetes 2009;58:609-19. [81] Parameswaran M, Tam PP. Regionalisation of cell fate and morphogenetic movement of the mesoderm during mouse gastrulation. Dev Genet 1995;17:16-28. [82] Kinder SJ, Tsang TE, Quinlan GA, Hadjantonakis AK, Nagy A, Tam PP. The orderly allocation of mesodermal cells to the extraembryonic structures and the anteroposterior axis during gastrulation of the mouse embryo. Development 1999;126:4691-701.

[83] Viotti M, Nowotschin S, Hadjantonakis AK. SOX17 links gut endoderm morphogenesis and germ layer segregation. Nat Cell Biol 2014;16:1146-56. [84] Kwon GS, Viotti M, Hadjantonakis AK. The endoderm of the mouse embryo arises by dynamic widespread intercalation of embryonic and extraembryonic lineages. Dev Cell 2008;15:509-20.

[85] Viotti M, Foley AC, Hadjantonakis AK. Gutsy moves in mice: cellular and molecular dynamics of endoderm morphogenesis. Philos Trans R Soc Lond B Biol Sci 2014;369. 
[86] Burtscher I, Lickert H. Foxa2 regulates polarity and epithelialization in the endoderm germ layer of the mouse embryo. Development 2009;136:1029-38. [87] Downs KM, Davies T. Staging of gastrulating mouse embryos by morphological landmarks in the dissecting microscope. Development 1993;118:1255-66.

[88] Gavrilov S, Lacy E. Genetic dissection of ventral folding morphogenesis in mouse: embryonic visceral endoderm-supplied BMP2 positions head and heart. Curr Opin Genet Dev 2013;23:461-9.

[89] Madabhushi M, Lacy E. Anterior visceral endoderm directs ventral morphogenesis and placement of head and heart via BMP2 expression. Dev Cell 2011;21:907-19.

[90] Withington S, Beddington R, Cooke J. Foregut endoderm is required at head process stages for anteriormost neural patterning in chick. Development 2001;128:309-20.

[91] Egea J, Erlacher C, Montanez E, Burtscher I, Yamagishi S, Hess M, et al. Genetic ablation of FLRT3 reveals a novel morphogenetic function for the anterior visceral endoderm in suppressing mesoderm differentiation. Genes Dev 2008;22:3349-62. [92] Maretto S, Muller PS, Aricescu AR, Cho KW, Bikoff EK, Robertson EJ. Ventral closure, headfold fusion and definitive endoderm migration defects in mouse embryos lacking the fibronectin leucine-rich transmembrane protein FLRT3. Dev Biol 2008;318:184-93.

[93] Kuo CT, Morrisey EE, Anandappa R, Sigrist K, Lu MM, Parmacek MS, et al. GATA4 transcription factor is required for ventral morphogenesis and heart tube formation. Genes Dev 1997;11:1048-60.

[94] Molkentin JD, Lin Q, Duncan SA, Olson EN. Requirement of the transcription factor GATA4 for heart tube formation and ventral morphogenesis. Genes Dev 1997;11:1061-72.

[95] Komada M, Soriano P. Hrs, a FYVE finger protein localized to early endosomes, is implicated in vesicular traffic and required for ventral folding morphogenesis. Genes Dev 1999;13:1475-85.

[96] Constam DB, Robertson EJ. Tissue-specific requirements for the proprotein convertase furin/SPC1 during embryonic turning and heart looping. Development 2000;127:245-54.

[97] Fristrom D. The cellular basis of epithelial morphogenesis. A review. Tissue Cell 1988;20:645-90.

[98] Gutzman JH, Graeden EG, Lowery LA, Holley HS, Sive H. Formation of the zebrafish midbrain-hindbrain boundary constriction requires laminin-dependent basal constriction. Mech Dev 2008;125:974-83.

[99] Keller R, Shih J, Domingo C. The patterning and functioning of protrusive activity during convergence and extension of the Xenopus organiser. Dev Suppl 1992:81-91.

[100] Rolo A, Skoglund P, Keller R. Morphogenetic movements driving neural tube closure in Xenopus require myosin IIB. Dev Biol 2009;327:327-38. [101] Skoglund P, Rolo A, Chen X, Gumbiner BM, Keller R. Convergence and extension at gastrulation require a myosin IIB-dependent cortical actin network. Development 2008;135:2435-44. 
[102] Keller R, Shook D. Dynamic determinations: patterning the cell behaviours that close the amphibian blastopore. Philos Trans R Soc Lond B Biol Sci 2008;363:1317-32.

[103] Keller RE, Danilchik M, Gimlich R, Shih J. The function and mechanism of convergent extension during gastrulation in Xenopus laevis. J Embyol exp Morph 1985;89:185-209.

[104] Keller R, Tibbetts P. Mediolateral cell intercalation in the dorsal, axial mesoderm of Xenopus laevis. Developmental Biology 1989;131:539-49. [105] Miyamoto DM, Crowther RJ. Formation of the notochord in living ascidian embryos. Journal of Embryology and Experimental Morphology 1985;86:1-17. [106] Warga RM, Kimmel CB. Cell movements during epiboly and gastrulation in zebrafish. Development 1990;108(4):569-80.

[107] Concha ML, Adams RJ. Oriented cell divisions and cellular morphogenesis in the zebrafish gastrula and neurula: a time-lapse analysis. Development 1998;125:983-94.

[108] Williams-Masson EM, Heid PJ, Lavin CA, Hardin J. The cellular mechanism of epithelial rearrangement during morphogenesis of the Caenorhabditis elegans dorsal hypodermis. Dev Biol 1998;204:263-76.

[109] Walck-Shannon E, Hardin J. Cell intercalation from top to bottom. Nat Rev Mol Cell Biol 2014;15:34-48.

[110] Walck-Shannon E, Reiner D, Hardin J. Polarized Rac-dependent protrusions drive epithelial intercalation in the embryonic epidermis of C. elegans. Development 2015;142:3549-60.

[111] Bertet C, Sulak L, Lecuit T. Myosin-dependent junction remodelling controls planar cell intercalation and axis elongation. Nature 2004;429:667-71.

[112] Nishimura T, Honda H, Takeichi M. Planar cell polarity links axes of spatial dynamics in neural-tube closure. Cell 2012;149:1084-97.

[113] Gubb D, Garcia-Bellido A. A genetic analysis of the determination of cuticular polarity during development in Drosophila melanogaster. J Embryol Exp Morphol 1982;68:37-57.

[114] Mlodzik M. Spiny legs and prickled bodies: new insights and complexities in planar polarity establishment. Bioessays 2000;22:311-5.

[115] Adler PN. Planar signaling and morphogenesis in Drosophila. Dev Cell 2002;2:525-35.

[116] Adler PN. The frizzled/stan pathway and planar cell polarity in the Drosophila wing. Curr Top Dev Biol 2012;101:1-31.

[117] Heisenberg CP, Tada M, Rauch GJ, Saude L, Concha ML, Geisler R, et al.

Silberblick/Wnt11 mediates convergent extension movements during zebrafish gastrulation. Nature 2000;405:76-81.

[118] Tada M, Smith JC. Xwnt11 is a target of Xenopus Brachyury: regulation of gastrulation movements via Dishevelled, but not through the canonical Wnt pathway. Development 2000;127:2227-38.

[119] Wallingford JB, Rowning BA, Vogeli KM, Rothbacher U, Fraser SE, Harland RM. Dishevelled controls cell polarity during Xenopus gastrulation. Nature 2000;405:815 . 
[120] Wallingford JB, Harland RM. Xenopus Dishevelled signaling regulates both neural and mesodermal convergent extension: parallel forces elongating the body axis. Development 2001;128:2581-92.

[121] Axelrod JD, McNeill H. Coupling planar cell polarity signaling to morphogenesis. ScientificWorldJournal 2002;2:434-54.

[122] Goodrich LV, Strutt D. Principles of planar polarity in animal development. Development 2011;138:1877-92.

[123] Wallingford JB. Planar cell polarity and the developmental control of cell behavior in vertebrate embryos. Annu Rev Cell Dev Biol 2012;28:627-53.

[124] Tissir F, Goffinet AM. Shaping the nervous system: role of the core planar cell polarity genes. Nat Rev Neurosci 2013;14:525-35.

[125] Gao B. Wnt regulation of planar cell polarity (PCP). Curr Top Dev Biol 2012;101:263-95.

[126] Shih J, Keller R. Patterns of cell motility in the organizer and dorsal mesoderm of Xenopus laevis. Development 1992;116(4):915-30.

[127] Shih J, Keller R. Cell motility driving mediolateral intercalation in explants of Xenopus laevis. Development 1992;116(4):901-14.

[128] Keller R, Shih J. Mediolateral intercalation of mesodermal cells in the xenopuslaevis gastrula. Bellairs, R, E J Sanders And J W Lash (Ed) Nato Asi (Advanced Science Institutes) Series Series A Life Sciences, Vol 231 Formation And Differentiation Of Early Embryonic Mesoderm; Nato Advanced Research Workshop, Banff, Alberta, Canada, October 25-27, 1991 Viii+341p Plenum Press: New York, New York, Usa; London, England, Uk 1992:47-61.

[129] Elul TM, Koehl MAR, Keller RE. Cellular mechanism underlying neural convergence and extension in Xenopus laevis embryos. Dev Biol 1997;191:243-58. [130] Kibar Z, Vogan KJ, Groulx N, Justice MJ, Underhill DA, Gros P. Ltap, a mammalian homolog of Drosophila Strabismus/Van Gogh, is altered in the mouse neural tube mutant Loop-tail. Nat Genet 2001;28:251-5. [131] Murdoch JN, Doudney K, Paternotte C, Copp AJ, Stanier P. Severe neural tube defects in the loop-tail mouse result from mutation of Lpp1, a novel gene involved in floor plate specification. Hum Mol Genet 2001;10:2593-601.

[132] Montcouquiol M, Rachel RA, Lanford PJ, Copeland NG, Jenkins NA, Kelley MW. Identification of Vangl2 and Scrb1 as planar polarity genes in mammals. Nature 2003;423:173-7.

[133] Song H, Hu J, Chen W, Elliott G, Andre P, Gao B, et al. Planar cell polarity breaks bilateral symmetry by controlling ciliary positioning. Nature 2010;466:378-82. [134] Curtin JA, Quint E, Tsipouri V, Arkell RM, Cattanach B, Copp AJ, et al. Mutation of Celsr1 disrupts planar polarity of inner ear hair cells and causes severe neural tube defects in the mouse. Curr Biol 2003;13:1129-33.

[135] Wang Y, Guo N, Nathans J. The role of Frizzled3 and Frizzled6 in neural tube closure and in the planar polarity of inner-ear sensory hair cells. J Neurosci 2006;26:2147-56.

[136] Hamblet NS, Lijam N, Ruiz-Lozano P, Wang J, Yang Y, Luo Z, et al. Dishevelled 2 is essential for cardiac outflow tract development, somite segmentation and neural tube closure. Development 2002;129:5827-38. 
[137] Wang J, Hamblet NS, Mark S, Dickinson ME, Brinkman BC, Segil N, et al. Dishevelled genes mediate a conserved mammalian PCP pathway to regulate convergent extension during neurulation. Development 2006;133:1767-78. [138] Ezan J, Montcouquiol M. Revisiting planar cell polarity in the inner ear. Semin Cell Dev Biol 2013;24:499-506.

[139] Murdoch JN, Henderson DJ, Doudney K, Gaston-Massuet C, Phillips HM, Paternotte C, et al. Disruption of scribble (Scrb1) causes severe neural tube defects in the circletail mouse. Hum Mol Genet 2003;12:87-98.

[140] Lu X, Borchers AG, Jolicoeur C, Rayburn H, Baker JC, Tessier-Lavigne M. PTK7/CCK-4 is a novel regulator of planar cell polarity in vertebrates. Nature 2004;430:93-8.

[141] Kibar Z, Torban E, McDearmid JR, Reynolds A, Berghout J, Mathieu M, et al. Mutations in VANGL1 associated with neural-tube defects. N Engl J Med 2007;356:1432-7.

[142] Kibar Z, Bosoi CM, Kooistra M, Salem S, Finnell RH, De Marco P, et al. Novel mutations in VANGL1 in neural tube defects. Hum Mutat 2009;30:E706-15. [143] Kibar Z, Salem S, Bosoi CM, Pauwels E, De Marco P, Merello E, et al. Contribution of VANGL2 mutations to isolated neural tube defects. Clin Genet 2011;80:76-82.

[144] Allache R, De Marco P, Merello E, Capra V, Kibar Z. Role of the planar cell polarity gene CELSR1 in neural tube defects and caudal agenesis. Birth Defects Res A Clin Mol Teratol 2012;94:176-81.

[145] De Marco P, Merello E, Rossi A, Piatelli G, Cama A, Kibar Z, et al. FZD6 is a novel gene for human neural tube defects. Hum Mutat 2012;33:384-90. [146] Robinson A, Escuin S, Doudney K, Vekemans M, Stevenson RE, Greene ND, et al. Mutations in the planar cell polarity genes CELSR1 and SCRIB are associated with the severe neural tube defect craniorachischisis. Hum Mutat 2012;33:440-7. [147] Jiang D, Munro EM, Smith WC. Ascidian prickle regulates both mediolateral and anterior-posterior cell polarity of notochord cells. Curr Biol 2005;15:79-85. [148] Jessen JR, Topczewski J, Bingham S, Sepich DS, Marlow F, Chandrasekhar A, et al. Zebrafish trilobite identifies new roles for Strabismus in gastrulation and neuronal movements. Nat Cell Biol 2002;4:610-5. [149] Wallingford JB, Harland RM. Neural tube closure requires Dishevelleddependent convergent extension of the midline. Development 2002;129:5815-25. [150] Jenny A, Darken RS, Wilson PA, Mlodzik M. Prickle and Strabismus form a functional complex to generate a correct axis during planar cell polarity signaling. EMBO J 2003;22:4409-20.

[151] Darken RS, Scola AM, Rakeman AS, Das G, Mlodzik M, Wilson PA. The planar polarity gene strabismus regulates convergent extension movements in Xenopus. EMBO J 2002;21:976-85.

[152] Goto T, Keller R. The planar cell polarity gene strabismus regulates convergence and extension and neural fold closure in Xenopus. Dev Biol 2002;247:165-81.

[153] De Marco P, Merello E, Cama A, Kibar Z, Capra V. Human neural tube defects: genetic causes and prevention. Biofactors 2011;37:261-8. 
[154] De Marco P, Merello E, Piatelli G, Cama A, Kibar Z, Capra V. Planar cell polarity gene mutations contribute to the etiology of human neural tube defects in our population. Birth Defects Res A Clin Mol Teratol 2014.

[155] Yen WW, Williams M, Periasamy A, Conaway M, Burdsal C, Keller R, et al. PTK7 is essential for polarized cell motility and convergent extension during mouse gastrulation. Development 2009;136:2039-48.

[156] Wong LL, Adler PN. Tissue polarity genes of Drosophila regulate the subcellular location for prehair initiation in pupal wing cells. J Cell Biol 1993;123:209-21.

[157] Yang JT, Rayburn H, Hynes RO. Embryonic mesodermal defects in alpha 5 integrin-deficient mice. Development 1993;119:1093-105.

[158] George EL, Georges-Labouesse EN, Patel-King RS, Rayburn H, Hynes RO. Defects in mesoderm, neural tube and vascular development in mouse embryos lacking fibronectin. Development 1993;119:1079-91. [159] Imuta Y, Koyama H, Shi D, Eiraku M, Fujimori T, Sasaki H. Mechanical control of notochord morphogenesis by extra-embryonic tissues in mouse embryos. Mech Dev 2014;132:44-58.

[160] Harris MJ, Juriloff DM. Mouse mutants with neural tube closure defects and their role in understanding human neural tube defects. Birth Defects Res A Clin Mol Teratol 2007;79:187-210. 


\section{FIGURE LEGENDS}

Figure 1. Stages of axial morphogenesis. Anterior is to the left in all images. Asterisks mark the position of the PNC, arrowheads indicate the position of the forming foregut pocket, and the small arrows indicate the inflection points defining the headfold region. A. Embryo at E7.5, before the major tissue shape changes. AVE, anterior visceral endoderm. B. Embryo at E7.75, showing neural plate $(\mathrm{np})$ formation. C. The same embryo shown in $B, 3$ hours later. The neural plate has begun the infolding process to form the head folds. D. A different embryo with head folds formed. E. The same embryo as in D, 10 hours later. The head folds have fully rotated, and the heart $(h)$ is now in its correct position posterior and ventral to the head folds. The change in distance between the bottom arrow and the asterisk in $\mathrm{D}$ and $\mathrm{E}$ indicates the progression of axial elongation. The images in $\mathrm{D}$ and $\mathrm{E}$ are from Movie 1.

Movie 1. Axial morphogenesis. Timelapse movie of development from the early headfold stage to 4 somites. This movie illustrates both the rotation of the heart primordium $(\mathrm{H})$ into its correct position by the elevation of the head folds $(\mathrm{HF})$, and the elongation of the axis concomitant with formation of the somites (S). The location of the primitive streak is indicated (PS). Anterior is to the left.

Movie 2. Mesoderm CE. Laser scanning confocal timelapse movie of CE in the paraxial mesoderm in an embryo of the EGFP-x strain. The posterior notochord (PNC), primitive streak (ps), and paraxial mesoderm (pm) are indicated.

Movie 3. Neural CE. Laser scanning confocal movie of CE in the neural plate in an embryo of the $\mathrm{mT} / \mathrm{mG}$ strain. Neural plate (np), posterior notochord (PNC) and somites (s) are indicated.

Figure 2. Competition of cell intercalation forces determines tissue shape. Mediolateral convergence (green arrows and protrusions) leads to tissue 
extension (dark blue arrows) and thickening (black arrows). Radial intercalation (magenta arrows and protrusions) counters the thickening, enhancing tissue extension. The relative magnitude of these two forces determines the ultimate shape of the tissue. An innate resistance of the tissue to extend (light blue arrows) is assumed. 


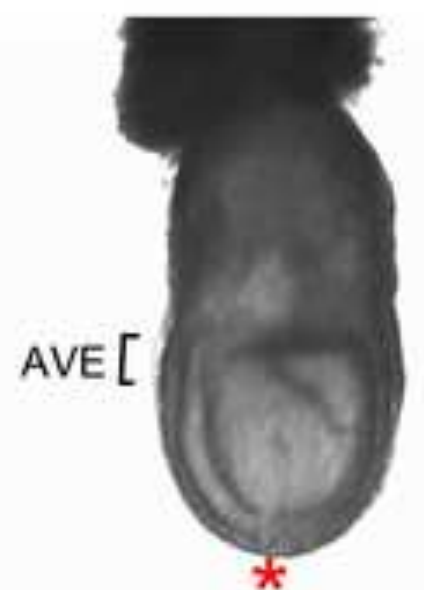

A

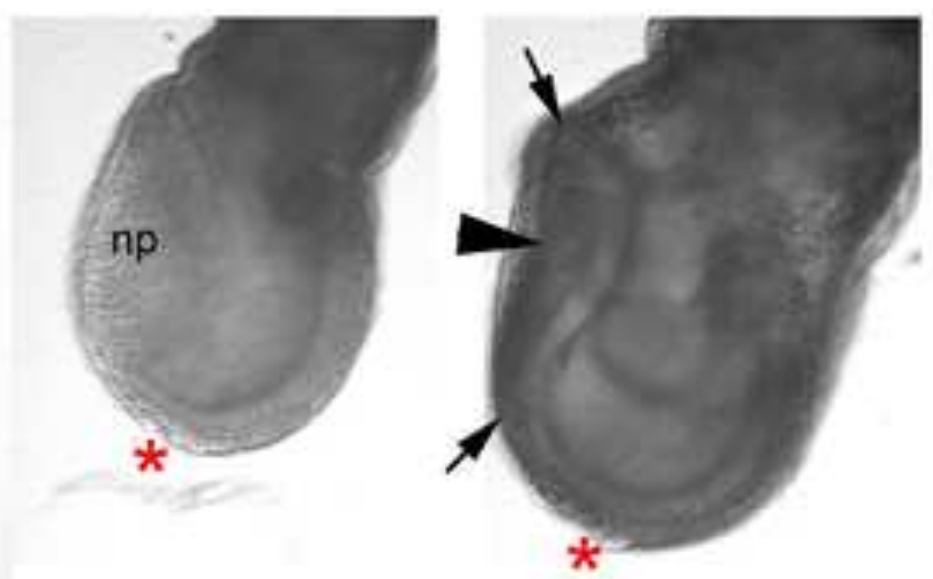

B

C
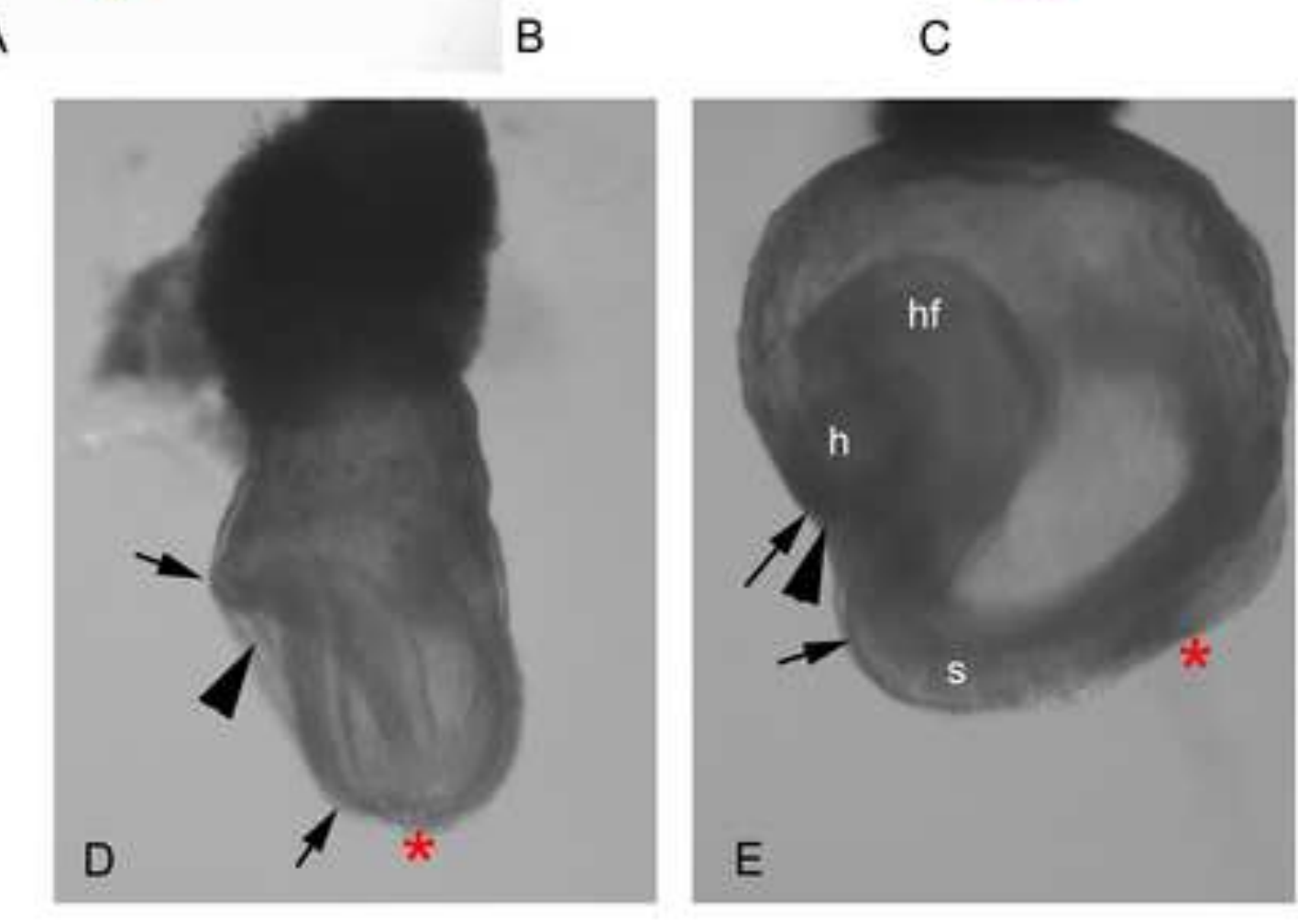
Mediolateral convergence tends to
produce radial de-intercalation or thickening.

Mediolateral convergence tends to
produce radial de-intercalation or thickening.

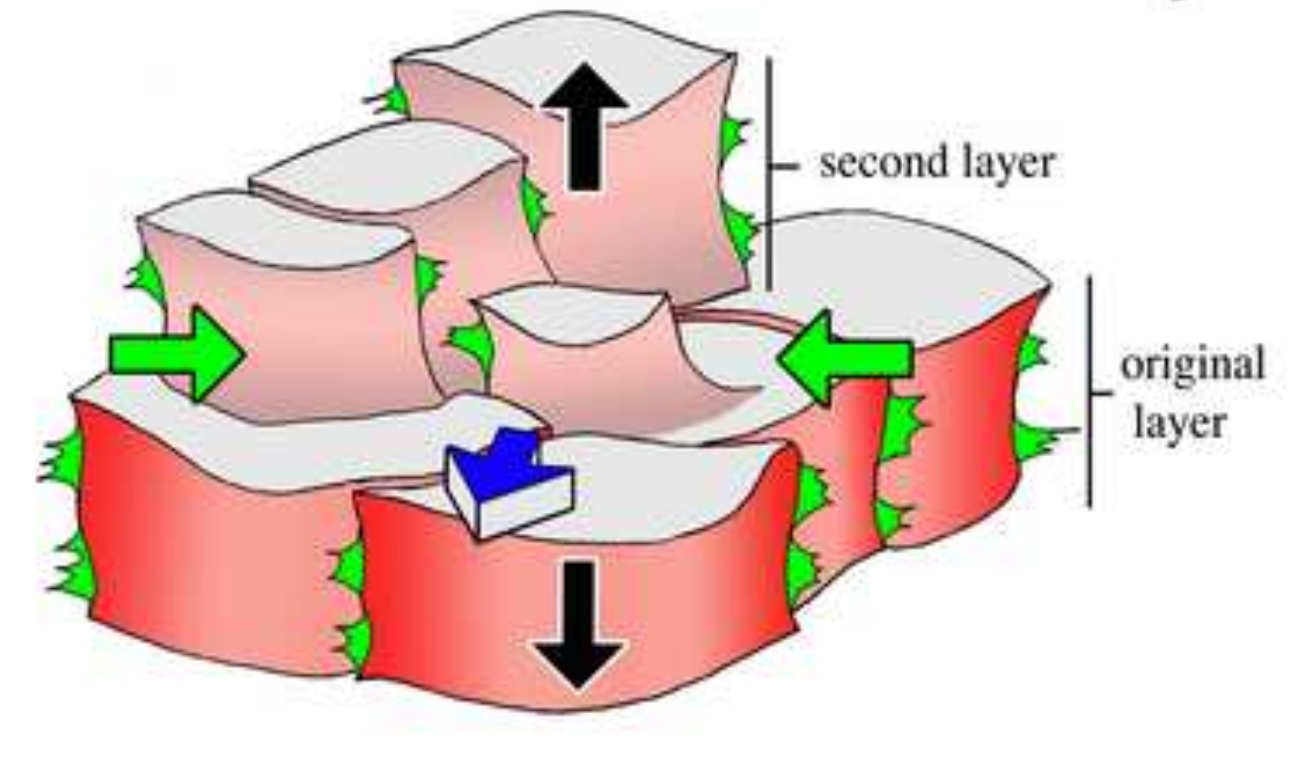

Radial intercalation
restores thinning

Radial intercalatio
restores thinning

Diagram of forces acting on the tissue
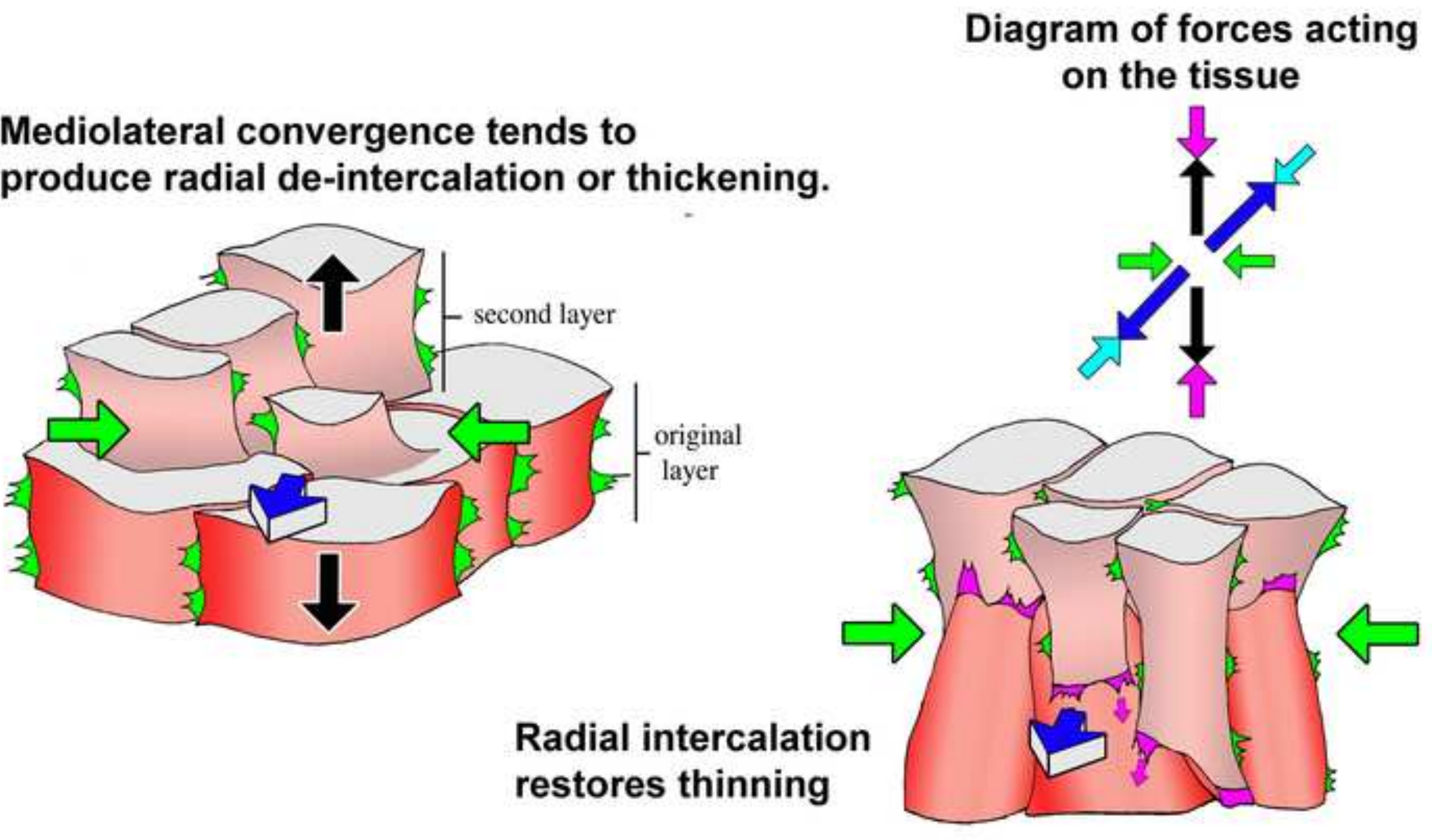

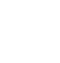

